\title{
Trifocal bone transport by llizarov technique for large post-traumatic tibial bone defects: a single centre BARI-ILIZAROV experience of 46 cases
}

\begin{abstract}
Purpose: The Aim of this study was to evaluate the clinical and functional outcome of patients with large post-traumatic tibial bone defects managed by Trifocal bone transport using the Ilizarov technique.

Methods: We retrospectively reviewed 46 cases of 38.2 years (range, 15.0-68.0years). The bone defects averaged $10.5 \pm 3.5 \mathrm{~cm}$ (range: $6.5 \mathrm{~cm}-20.5 \mathrm{~cm}$ ) after radical debridement and it was managed by trifocal bone transport.

Results: The mean duration of follow up after Ilizarov frame removal was $28.5 \pm 1.5$ months (range 10.0-24.0months). All patients achieved complete union in both the regenerates. The mean bone transport time was $50.6 \pm 20.5$ days (range 30.0-130.0days). The mean Ilizarov fixator time was $1.2 \pm 0.4 \mathrm{months} / \mathrm{cm}$ (range $0.8-2.2 \mathrm{months} / \mathrm{cm}$ ). The bone results were excellent in 40 patients and good in 6 patients. The functional results were excellent in 42 patients and good in 4 patients.
\end{abstract}

Conclusion: Trifocal bone transport is a safe, reliable and successful methods for large post-traumatic tibial bone defects in one stage surgery.

Keywords: bone defects, bone transport, Ilizarov technique, trifocal approach
Volume I2 Issue I - 2020

\author{
Mofakhkharul Bari,' Islam Shahidul, ${ }^{2}$ Bari AM \\ Shayan $\mathrm{R}^{3}$ \\ 'Chief Consultant, Bari-llizarov Orthopaedic Centre,Visiting and \\ Honored Prof., Russian llizarov Scientific Centre, Bangladesh \\ ${ }^{2}$ Professor, FCPS, Bari-llizarov Orthopaedic Centre, Bangladesh \\ ${ }^{3}$ Medical officer, Bari-llizarov Orthopaedic Centre, Bangladesh
}

Correspondence: Mofakhkharul Bari, Chief Consultant, BariIlizarov Orthopaedic Centre,Visiting and Honored Professor, Russian llizarov Scientific Centre, Kurgan, I/I, Suvastu Shirazi Square, Lalmatia, Dhaka- I207, Bangladesh, Tel +88 01819 2II595, Email bari.ilizarov3।@gmail.com

Received: January 23, 2020 | Published: February 07, 2020

\section{Introduction}

Post-traumatic large bone tibial and soft tissue defects following high energy trauma presents a great challenge for Orthopaedic and Reconstructive surgeons. Bone transport by Ilizarov technique is the gold standard method for the treatment of large bone defects. Nonunion, deformity, persistent infection, bone defect and shortening can be addressed simultaneously using the academician Ilizarov principles and technique. ${ }^{1-3}$ The Ilizarov method is divided into 3 categories depending on the type of treatment.

\section{a. Acute shortening and lengthening (monofocal approach) \\ b. Single level-bone transport (bifocal approach) and \\ c. Double level-bone transport (trifocal approach). ${ }^{4}$}

The monofocal approach closes bone and soft tissue defects directly. Acute shortening $>3 \mathrm{~cm}$ may compromise the vasculature and lead to limb ishchaemia. The fibula must have a defect to match the tibial defect. ${ }^{4}$ Conventional single level bone transport bridged bone defects in the majority of cases, when the defect is $>7 \mathrm{~cm}$, the complications of bone transport including prolonged fixation in the Ilizarov frame, hypoplastic bone formation in the regenerate tend to increase. ${ }^{4,5}$ Kurgan, Russia researches proposed that trifocal bone transport should be used to reduce those complications when bone defect is $7 \mathrm{~cm}$ or greater. ${ }^{1,4,6}$ In this original paper we are presenting our experience in successful treatment of large post-traumatic tibial bone and soft tissue defects by trifocal bone transport using the Ilizarov technique in a series of 46 cases where conventional orthopaedic approaches are often inadequate and inappropriate.

\section{Materials and methods}

We respectively reviewed a series of 46 patients who were managed with the Ilizarov technique of bone transport between January 2005 and January 2018 at our Bari-Ilizarov Orthopaedic Centre. The inclusion criteria's were the following-

a. Patients aged 15 years or older.

b. Post-traumatic segmental bone defect treated by trifocal bone transport.

c. Bone defects $\geq 7 \mathrm{~cm}$.

In this study included 36 males and 10 females with a mean age of 38.2 years (range, 15.0-68.0 years). The causes of injury included motor vehicle accidents in 30 patients, explosive injury in 5 patients, crush-related injury in 10 patients and fall from height in one patient. All were open fractures, including Gustilo II in 7, Gustilo IIIA in 15, Gustilo IIIB in 20, and Gustilo IIIC in 2 patients. The mean duration from time of injury to application of the Ilizarov frame was 15.5 months (range, 2.0-40.0months). Defects with infection were located in the proximal tibia in 16 patients, the middle tibia in 21 patients and the distal tibia in 10 patients.

\section{Surgical procedure}

The patient was in supine position under spinal anesthesia. All implants were removed. Radical debridement of all inflammatory granulation tissues and infected devitalized bones were performed. ${ }^{7}$ Soft tissue and bone specimens were sent for culture. The mean area 
of soft tissue defect after debridement was $8.5 \mathrm{~cm} \times 5.5 \mathrm{~cm}$ (range: $5.5 \mathrm{~cm} x 2.5 \mathrm{~cm}$ to $20.0 \mathrm{cmx} 10.0 \mathrm{~cm}$ ), and the mean bone defects was $10.5 \pm 3.5 \mathrm{~cm}$ (range: $5.5 \mathrm{~cm}-20.5 \mathrm{~cm}$ ), which were measured intraoperatively. After the debridement Ilizarov frame was applied for every patient. For mid tibia defect, two rings were placed in the proximal and two rings in the distal tibia. Sometimes we put 3 rings in the distal tibia for more stability. Two corticotomies were performed: one in the proximal and other in the distal tibia between each of the rings. Converging transport was performed. All cases were followed by bone transport and resume limb length.

\section{Follow-up}

Bone transport started after a latent of 5 to 7 days. For converged bone transport, each fragment of both sides of the bone defect proceeded at a rate of $1 \mathrm{~mm} /$ day, which was divided into 4 times of $0.25 \mathrm{~mm}$ each. Thus, the distraction rate at each site of corticotomy should be $1 \mathrm{~mm} /$ day, and the bone defect was shortened $2 \mathrm{~mm} /$ day. The modes of trifocal approach (double level bone transport) are shown in the diagrams (Figure 1).

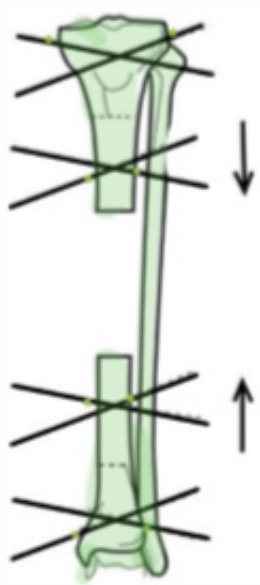

a.

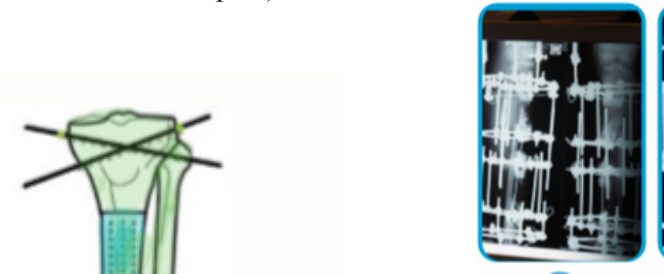

complete union in both the regenerates. The mean bone transport time was 50.6 \pm 20.5 days (range 30.0-130.0days). The mean soft tissue healing duration was $2.5 \pm 3.0$ months (range, 1.0-5.0months). The mean consolidation duration of the distraction gap was $10.8 \pm 3.0 \mathrm{months} / \mathrm{cm}$ (range, 5.0-16.0months $/ \mathrm{cm}$ ). The mean Ilizarov fixator time was $12.0 \pm 0.4 \mathrm{months} / \mathrm{cm}$ (range, $0.8-2.2 \mathrm{months} / \mathrm{cm}$ ). The bone results were excellent in 40 patients and good in 6 patients. The functional results were excellent in 42 patients and good in 4 patients. The typical case is illustrated in Figure 2.
(E)

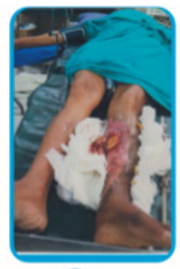

A

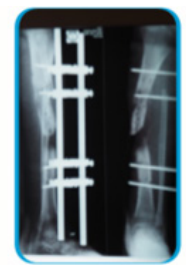

B

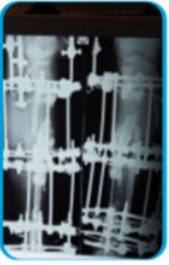

F

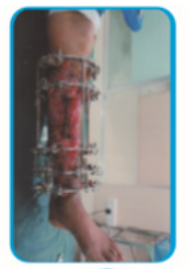

C

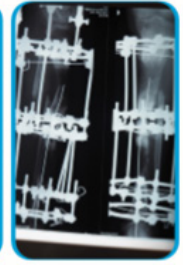

G

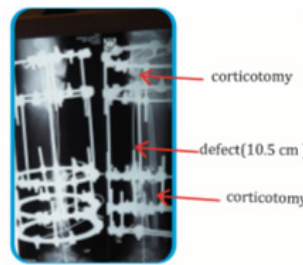

D
Figure 2 (A) Picture of 35 years old man with G III B. (B) Radiograph of left tibia-fibula with uniaxial fixator in situ, done elsewhere. (C) Picture of left leg with llizarov in situ. (D) Radiograph of left tibia-fibula after debridement with proximal \& distal corticotomy. (E) Radiograph of left tibia-fibula with llizarov in situ after 2 months. (F) Radiograph of left tibia-fibula after 3 months. (G) Radiograph of left tibia-fibula after II months. (H) Final radiograph of left tibia-fibula after I year and 6 months. (I) Clinical picture of the patient.

In all our cases no flap cover was needed and bone transport was achieved nicely. Bone grafting was not done in any case and that is the violation of the Ilizarov principles and rule. We achieved good contact in the docking site in all the cases. The soft tissue defects were closed gradually during bone transportation. We put guide wire in the whole tibia to maintain the axis and to prevent the deviation. One nonunion occurred at the docking site due to invaginated soft tissue, and refreshened the bone ends and achieved a good contact and excellent union.

\section{Discussion}

The management of large post-traumatic tibial bone and soft tissue defects remains a challenge for Orthopaedic and Reconstructive surgeons. Conventional treatments have been proposed, including flap transfer with combined or autologous bone grafting, vascularized fibular grafts, Masquelet technique, and bone transport., ${ }^{1,4}$ Autologous bone graft is geared toward smaller defects typically because of its limited quantity; for larger defects, graft is harvested from more than one site, increasing the morbidity of the donor site (Table 1-3). Furthermore; even though vascularized fibular grafts have been successfully used to bridge massive bone defects, the operation demands high technical expertise and causes great trauma, and complications of stress fracture and nonunion have usually occurred..$^{1-5}$ Masquelet technique can reconstruct large bone defect, but the procedure requires two steps to complete, including debridement, spacer insertion and wound closure, and bone graft is 
performed six to eight weeks later. For large bone defects, the source of bone graft is a big problem. ${ }^{5,9}$ Ilizarov bone transport has become a gold standard for the treatment of massive tibial bone defects, it could eradicate infection and solve bone and soft tissue defects at the same time. ${ }^{1}$ Traditional Ilizarov bone transport universally adopts single level transport to bridge massive bone defects. The drawbacks of the method are the lengthy Ilizarov frame time. Several studies of single level bone transport have shown that the Ilizarov fixation index ranges from 1.2 to 2.8 months $/ \mathrm{cm}$ with an average of $2.0 \mathrm{months} /$ $\mathrm{cm} \cdot{ }^{1,4,7,8,10}$ According to the calculation, if the size of bone defect is $10 \mathrm{~cm}$, Ilizarov fixation takes more than 20 months. To decrease the fixation time, Borzunov et al. ${ }^{6}$ firstly proposed that one-stage double level or multilevel bone transport for massive bone defect to shorten distraction time and Ilizarov fixation time. Their clinical outcomes demonstrated that the duration of distraction could be reduced 2.5 times and fixation from 1.3 to 1.9 times with the double level technique compared with the traditional single level technique. In our study, the average size of bone defect was $10.9 \pm 3.8 \mathrm{~cm}$. The mean compression/ distractions $50.6 \pm 20.5$ days and the mean Ilizarov fixator time was $1.2 \pm 0.4$ months $/ \mathrm{cm}^{11,12}$

Borzunov et al..$^{5}$ believed that hypoplastic bone formation could happen during defect filling when a single-level distraction regenerate was grown to $>5 \mathrm{~cm}$ or to the length that exceeded $40 \%$ of the original segment. All bone defects of our patients are $>7.0 \mathrm{~cm}$ and averaged at $1 \mathrm{~cm}$. According to our observations and experiences, we consider using double level transport if the defect is $\geq 7.0 \mathrm{~cm}$. This could facilitate earlier docking at the bone defect site. We encountered one delayed union or non-union of the docking site as a result of soft tissue interposition, poor blood supply, and poor contact from mismatch of coapting surface.

In conclusion, the Ilizarov technique of trifocal bone transport is a safe, reliable and successful methods for large post-traumatic tibial bone defects in one stage surgery. It could significantly shorten frame time, decrease bone transport time, and reduce total treatment time.

\section{Acknowledgments}

None.

\section{Conflicts of interest}

All authors declare no conflict of interest.

\section{Funding}

None.

\section{References}

1. Sala F, Thabet AM, Castelli F, et al. Bone transport for post infectious segmental tibial bone defects with a combined Ilizarov/Taylor spatial frame technique. J Orthop Trauma. 2011;25(3):162-168.

2. Ilizarov GA. Transosseous Osteosynthesis theoretical and clinical aspects of the regeneration and growth of tissue. Germany: SpringerVerlag Berlin Heidelberg; 1992:453-543.

3. Bari MM. A color atlas of limb lengthening, surgical reconstruction and deformity correction by Ilizarov technique. 2013:127-139.

4. Paley D, Maar DC. Ilizarov bone transport treatment for tibial defects. $J$ Orthop Trauma. 2000;14(2):76-85.

5. Borzunov DY, Chevardin AV. Ilizarov non-free bone plasty for extensive tibial defects. Int Orthop. 2013;37(4):709-714.

6. Borzunov DY. Long bone reconstruction using multilevel lengthening of bone defect fragments. Int Orthop. 2012;36(8):1695-1700.

7. Forsberg JA, Potter BK, Ciemy G 3rd, et al. Diagnosis and management of chronic infection. J Am Acad Orthopaed Surg. 2011;19(Suppl 1):S8S19.

8. Fischgrund J, Paley D, Suter C. Variables affecting time to 40 " bone healing during limb lengthening. Clin Orthop Relat Res. 1994;301:31-37.

9. Masquelet AC, Fitoussi F, Begue T, et al. Reconstruction of the long bones by the induced membrane and spongy autograft. Ann Chir Plast Esthet. 2000;45(3):346-353.

10. Paley D. Principles of deformity correction. Knee extension contracture. Germany: Orthopedics, Springer; 2002:195-234.

11. Gustilo RB, Anderson JT. JSBS classics. Prevention of infection in the treatment of one thousand and twenty-five open fractures of long bones. Retrospective and prospective analyses. J Bone Joint Surg Am. 2002;84(4):682.

12. Paley D, Catagni MA, Argnani F, et al. Ilizarov treatment of tibial nonunions with bone loss. Clin Orthop Relat Res. 1989;241:146-165. 